\title{
Partnership Functioning: A Case in Point Between Government, Nongovernment, and a University in Australia
}

\author{
Saras Henderson, PhD, MEd, RN ${ }^{1}$,Elizabeth Kendall, $\mathrm{PhD}^{2}$, Peter Forday ${ }^{3}$, and Debbie Cowan ${ }^{4}$ \\ (1) Population and Social Health Research Program, Griffith Health Institute, School of Nursing and Midwifery, Griffith University, (2) Population and Social Health Research \\ Program, Griffith Health Institute, Centre for National Research on Disability and Rehabilitation Research, Griffith University, (3) Population and Social Health Research \\ Program, Griffith University, (4) Population and Social Health Research Program, Griffith University and Queensland Health
}

Submitted 29 November 2012, revised 22 August 2012, 6 December 2012

\section{Abstract}

Background: Culturally and linguistically diverse (CALD) communities in Queensland, Australia, do not access health services, contributing to poor health outcomes. To improve health in CALD communities, a partnership was formed between the state government, two nongovernment CALDspecific organizations (NGOs), and a university to develop a service that could facilitate health service use. This qualitative research explored the partners' perspectives on how the partnership functioned and its outcomes.

Objectives: We sought to (1) explore how participants engaged with the principles of partnership, the processes they used, and their beliefs about the facilitators and barriers to intersectoral collaboration and (2) gain insights into how the partners perceived the development and functioning of the partnership.

Methods: Qualitative, semistructured interviews were conducted with each of the key stakeholders in the partnership $(n=4)$. A focus group was also conducted with those working within the two NGO partners in the delivery of the service $(n=8)$. Open-ended questions drawn from the literature on partnership principles were used to guide the interviews and focus group data collection. The data were transcribed and analyzed using thematic principles.
Results: The four themes identified were: (1) Perceived benefits of the partnership outweighed organizational differences; (2) respectful relationships sustained the partnership; (3) mitigating conflict enabled the purpose of the partnership to be fulfilled; and (4) a neutral interpersonal space enabled the partnership to be enacted.

Conclusions: Our study showed how contextual pressures created within the system can damage tenuous connections that have been developed between otherwise competitive organizations, leading to dissolution of partnerships. However, the study has also shown that partnerships may be purpose and time bound, not necessarily with respect to longevity. Through strategic negotiations, partnerships can be sustained until the goal of the partnership is attained, which in this instance was the development of a new service delivery model.

\section{Keywords}

Partnerships, CALD communities, government and nongovernment organizations (NGO), partnership process, partnership principles
I nterorganizational partnerships have become popular in the health service arena because they are thought to encourage innovation in addressing social and community problems. ${ }^{1-4}$ Specifically, they are thought to yield advantages such as greater efficiency in providing quality services. ${ }^{5-7}$ Partnerships often include a mix of public, private and nonprofit organizations because, as a collective, they are assumed to be able to take a broader perspective and generate innovation. NGOs are seen as a valuable component of this collective because they can address local community problems in a decentralized manner within shorter time periods as a result of their tacit knowledge of the community. ${ }^{7}$

In Queensland, Australia, a partnership was formed between four organizations after consultations with local com- 
munity leaders that revealed poor access to services and less than optimal health outcomes in the local CALD populations. The purpose of the partnership was to develop a model that could improve health service access for CALD communities by capitalizing on the strengths and processes that existed within the community networks. ${ }^{8}$

The four partners included the state government health service, which funded the project, a university, and two specialist CALD NGOs. The two NGOs brought local knowledge, connections, and expertise about working with CALD communities. The university brought expertise and skills in evidence-based model development, participatory research methods, implementation, and evaluation. This group of partners was considered optimal because it could facilitate solutions based on both academic and practice knowledge. ${ }^{9}$

The mandate for the partnership was to provide project management, evidence of community liaison, educational expertise, and infrastructure. The university contributed personnel in the form of expertise in project design, community engagement, consultation, and evaluation. The two NGOs provided organizational support for the model. Over the next 2 years of collaboration, a new model was successfully developed and implemented by the partnership. The final model was based on a collaborative community-driven approach, utilizing local community members who were trained and supported to act as community navigators. ${ }^{*}$ The navigators provided a bridge between the CALD communities and the health system, leading to an increase in health service utilization and a greater awareness of health in the communities. The navigators assessed client needs, facilitated health promotion, and supported community members to access health services.

The Oxford Dictionary defines partnership as "a cooperative relationship between people who agree to share responsibility for achieving some specific goals." From a developmental perspective, the term 'partnership' has connotations of equitable relationships between the parties, when in reality there are inherent differences between parties that can stand in the way of equity and collaboration. ${ }^{10}$ According to Gazley, ${ }^{11}$ partnerships are often fraught with difficulties because different organizations operate from different value systems, phi- losophies, and have different agendas that drive their business. Even among NGOs, where the balance of power is relatively equal and the value systems are likely to be similar, partnerships can be difficult. For example, NGOs are often reliant on competitive tendering for funds, competing against each other in ways that can be problematic when they are brought together to work collaboratively for the greater good. ${ }^{12,13}$

Although there is ample literature describing the benefits of partnerships between organizations, there is a dearth of information about how partnerships can be developed or how they function. ${ }^{14-16}$ Although issues are likely to be similar across partnerships, the processes in which partners engage to resolve issues can be different. ${ }^{14-16}$ This paper explores the partners' perspectives on how the partnership functioned and the processes they used to manage issues, such as, sharing ideas, commitment, involvement in decision making, ensuring transparency, managing competition, enhancing accountability, and seeking sustainability. The facilitators and barriers that affected the partnership were examined, together with the manner in which they addressed the challenges, overcame difficulties, and worked within a participatory governance framework.

\section{METHODS}

The research was conducted between 2009 and 2010 with ethics approval from both the University and State Government Research Ethics Committees. A qualitative approach was used to explore, and describe the perceived functioning of the partnership and the processes that were used according to the partnership members. Individual interviews $(n=4)$ were first conducted with the state government project officer, the chief executive officers from each of the NGOs, and the lead researcher from the university. A focus group interview was conducted with the team coordinator and seven of the nine navigators $(n=8)$ who were employed within the two NGOs to deliver the new service. Two navigators were unavailable at the time of the interview. According to Morgan, ${ }^{17}$ the group interview is a form of qualitative research that relies on group interaction to elicit insights about a topic of interest that may not be accessible via one-to-one interview. This method was considered most appropriate given the way in which the group

For a full description of the service, see Henderson, S., \& Kendall, E. 'Community navigators': Making a difference by promoting health in culturally and linguistically diverse (CALD) communities in Logan, Queensland. Aust J Primary Health. 2011;17:347-54. 
of navigators had supported each other and worked collectively from the beginning of the project. Further, the collective nature of their communities meant that some navigators were uncomfortable being singled out for an individual interview.

Using an unstructured conversation style of interview, prompt questions focused on how participants engaged with the principles of partnership, the processes they used, and their perspectives of the facilitators and barriers encountered in the partnership. ${ }^{17-19}$ The discussions centered on relationships, decision making, and the partnership experience, as well as the purpose of the partnership and its benefits within the context of each organization's structure and values. The discussions also focused on issues such as conflict, competition, tension, difficulties, challenges, and funding, as well as the processes used to overcome difficulties including strategies to enhance the partnership, outcome, and sustainability. The interviews lasted approximately 1 hour each and the focus group lasted 90 minutes.

During the conversations, probing questions were used to follow up on responses and encourage participants to give concrete examples. Congruent with qualitative research, the interviews were transcribed verbatim and analyzed manually using a thematic method of constant comparison. First, the data were examined line by line for significant words and phrases, which were extracted and coded into categories. Similar categories were identified across the interviews and data were clustered accordingly. Clusters were then compared against each other to ensure they were sufficiently distinct to develop thematic headings. ${ }^{20}$ Using these headings, final themes were developed, which were then reviewed and agreed upon by the key participants (i.e., partnership members) to ensure credibility of the data. ${ }^{20}$ Some key representative quotes were selected to best represent each theme.

\section{RESULTS}

Data analysis revealed four main themes: (1) Perceived benefits of the partnership outweighed organizational differences, (2) respectful relationships sustained the partnership, (3) mitigating conflict enabled the purpose of the partnership to be fulfilled, and (4) neutral interpersonal space enabled the partnership to be enacted. These themes reflected the key strategies stakeholders believed were critical to the ability of the partnership to achieve its purpose.
Theme 1: Perceived Benefits of the Partnership Outweighed Organizational Differences

In the current example, there was a long history of competition between the two NGOs involved in our partnership, which raised significant challenges for the process. Both NGOs provided health services for CALD and refuge/migrant clients in the same region. Although the NGOs gained funding from sponsors and philanthropic organizations, they also competed for project funds from the government. Therefore, in the current partnership, the NGOs were placed in a difficult position of having to preserve their unique identity and competitive advantage at the same time as maintaining an equitable and collegial relationship within the partnership. To partially address this issue in the current partnership, the two NGOs carved out specific target populations and processes that were unique to their organizations. This decision provided them with time to adjust to the idea of the partnership and to establish the norms of partnership working without the complications created by competition. Similarly, funding was initially distributed evenly across the two NGOs to reduce the need for competition. These measures were important initially to encourage collaboration; over time, however, the benefits of the partnership seemed to overshadow the history of competition.

All participants stated that forming the partnership had significant benefits for the CALD communities they served, and that these benefits overrode the discomfort that was created by their history of competitiveness. Participants stated that the mix of government, nongovernment, and university brought diverse skills and expertise to the identification of a solution to a complicated and multifaceted problem such as low health service utilization in CALD communities. This indicated that the eventual model could only be sustained through these organizations working together, giving potential to deliver more outcomes than could be delivered by a single entity. The partnership allowed different groups to identify strategies collectively and encouraged creative responses in financially constrained circumstances. The participants all stated that the partnerships offered a unique opportunity for organizations with different values, philosophies, and skills to pull together to achieve important service delivery outcomes.

In a subsequent funding round, the NGO partners suggested that equally sharing the funding was not the best 
method because it resulted in duplication and wastage. Thus, over time, the partners had developed a belief that the benefits of the service were more important than any advantage that could be gained from the partnership for the own organizations. Table 1 depicts participants' comments that reflected the benefits they perceived as being generated by the partnership.

\section{Theme 2: Respectful Relationships Sustained the Partnership}

Most participants stated that a respectful relationship between the partners was a key ingredient enabling the successful development of the model. They reported that the partnership allowed them to come together and collaborate with open dialogue and build a respectful relationship, thus paving the way for integrated activity despite the competitive context in which they operated. The participants were of the view that everyone's opinion was heard and everyone was treated with respect and integrity. They were engaged throughout the entire process, receiving regular updates and ample opportunities to raise or address issues, indicating an inclusive process. However, participants indicated that although respectful relationship building was important in some ways, respectfulness hindered progress. For example, the participants explained that at times members were expending such high levels of energy on diplomacy that they sometimes failed to engage in robust discussions that acknowledged differences. They viewed this situation as a lost opportunity to be honest about their motivations and drivers. Some participants reported that too much time was devoted to building relationships rather than getting on with the project. They explained that although they understood the need to build trust, especially where there was competitiveness between partners, they preferred the time spent to be more balanced. This conclusion raised an interesting dilemma for partnership managers who need to perform this balancing act. Table 2 shows the advantages and disadvantages of maintaining respect.

Even though the partners were independently and collectively motivated by the need to improve services for the target population, they recognized external funding as an incentive for collaborative work. They indicated that the government was strategic in wanting the two NGOs to partner because they both provided health services to CALD communities and were in an optimum position to roll out a new model. The current partnership was important from the perspective of governance to make sure the model was implemented fairly and thoroughly. Participants suggested some strategies to achieve respectful relationships (Table 3).

Theme 3: Mitigating Conflict Enabled the Purpose of the Partnership To Be Fulfilled

Participants faced a number of conflicts during the partnership, both operational and conceptual. For instance, participants encountered conflict in relation to discussions about which CALD communities would be the focus of the model. These discussions occupied many meetings until the model was due to be implemented. Owing to time constraints and competing demands, their main source of communication

\begin{tabular}{|l|l|}
\hline Benefits & Participant Comments \\
\hline Skill mix assist to complete task & $\begin{array}{l}\text { To have research behind it - the university, government, NGOs - the three-level partnership has } \\
\text { been key to our successful outcome with limited resources, }\end{array}$ \\
Sustainability of the outcome & $\begin{array}{l}\text { I think the purpose was to actually be able to do more, do more complex things and do it in a } \\
\text { sustainable way ...partnership is the way to go. }\end{array}$ \\
Build community capacity & $\begin{array}{l}\text { Without working together, between multicultural services, government, and the academic } \\
\text { institution, it will be hard, to address the complex nature of CALD communities ... these } \\
\text { communities need to work with you and try and help themselves. Partnership is important to } \\
\text { collectively build the communities' trust, which will help educate them .... we need to put our } \\
\text { differences aside to work together. }\end{array}$ \\
There is a systemic outcome for this partnership, it can lead to a model of collaboration that is \\
innovative ... we can be creative and be accountable at the same time .... On your own you have all \\
these constraints that can kill creativity.
\end{tabular}

NGO, nongovernment organization. 
became e-mail, which sometimes caused misunderstandings and led to unwarranted tension within the partnership. Participants reported that the lack of face-to-face contact later in the partnership was detrimental, although unavoidable. Funding issues caused the most conflict within the partnership, especially between the two NGOs. Historically, these organizations had been forced to compete for the same, limited government funding. Nevertheless, the participants acknowledged that the vision was so important that it enabled them to put their differences aside and engage in a number of collaborative strategies to successfully develop the model.
Table 4 shows the conflicts and the strategies that were used.

The NGO partners explained that when they had previously received government funding, it had compounded the tension between the organizations, rather than facilitating open communication. They believed that in the past the politics between them had been managed by the government rather than letting them work it out between themselves. This project was seen as an opportunity to demonstrate their capacity to work cooperatively for a common purpose.

Participants reported that they resolved tensions within the partnership by being transparent in the funding arrange-

\begin{tabular}{|c|c|}
\hline \multicolumn{2}{|r|}{ Participant Comments } \\
\hline \multicolumn{2}{|r|}{ Advantages } \\
\hline Inclusive engagement & $\begin{array}{l}\text { Updated in the progress of the process ... clear information, good data, good statistics, and a lot of openness } \\
\text { towards dialogue, the ability to contribute. I never felt like my contributions were ignored or treated } \\
\text { disrespectfully. I felt I was treated with integrity. }\end{array}$ \\
\hline Promoted collaboration & $\begin{array}{l}\text { I think the successful conduct and impact of the project were testament to how effectively the partnership was } \\
\text { managed by the key players. }\end{array}$ \\
\hline \multicolumn{2}{|r|}{ Disadvantages } \\
\hline \multirow[t]{2}{*}{ Delayed progress } & $\begin{array}{l}\text { I think we were really good at being diplomatic with each other that we were not really honest about issues ... } \\
\text { it would have been good to be more direct and more brutal, but respectful, in a way that we could fully address } \\
\text { issues because at various times, things were not fine [conflict]. We just needed people to understand that we } \\
\text { are not critical about the person ... it is about process. }\end{array}$ \\
\hline & $\begin{array}{l}\text { Sometimes the meetings would go on around in circles because nobody was game to say 'hey what is going on } \\
\text { here? It doesn't match with what my organization is about, why is this happening?' We kind of pussy-footed } \\
\text { around so as not to upset anybody. }\end{array}$ \\
\hline Time consuming & $\begin{array}{l}\text { We spent too much time working on relationship building and not "doing" [progressing the project] ... we } \\
\text { could have had a balance ...I would have amplified a conflict early on and pushed and prodded and provoked } \\
\text { everyone into addressing that and unpacking the conflict so it can be resolved ... but we did not do this as } \\
\text { we wanted to be respectful to the parties involved in the sensitivities and this delayed resolving conflict and } \\
\text { slowed the project. }\end{array}$ \\
\hline
\end{tabular}

Table 3. Strategies to Achieve Balance in Respectful Relationships

\begin{tabular}{|ll|}
\hline Strategies & Participant Comments \\
\hline Ground rules & $\begin{array}{l}\text { How do we manage that? We could have been really clear about ground rules and encouraged each other } \\
\text { to 'name' the issues and debate them openly. One strategy we could have used was to have robust and open } \\
\text { discussion about divergent opinion, even if this resulted in difficult conversations. }\end{array}$ \\
Preserving identity & $\begin{array}{l}\text { It's like walking on egg shells when all the partners are trying to keep their organizations functioning .... } \\
\text { everybody does have an agenda and they all have got to be supported ...just because they are in a partnership } \\
\text { doesn't mean that they lose their own agenda and their identity. It is hard when you are historically competing } \\
\text { with your partner for funds in one arena but we are asked to work in partnership in another area .... this can be } \\
\text { tough but I must say the partners managed admirably to overcome such difficulties. }\end{array}$
\end{tabular}

CALD, culturally and linguistically diverse; NGO, nongovernment organization. 
ments. As noted, when the first wave of funding became available to begin the new service, a decision was made to award each NGO equal funds. Although it was thought initially that this decision would promote transparency and equity, in reality it caused a different concern. Participants observed that this equal split of the available funds resulted in insufficient resources and duplication of administrative costs. Participants believed that the implementation of the model should be handled by the organization that was best placed to deliver the model. As a result, subsequent funding was managed through a competitive tender process at the request of the two NGOs. Ironically, this decision effectively dissolved the partnership because funds were delivered to only the successful NGO. However, the successful NGO continues to deliver the new service, suggesting that partnerships may need to be time limited vehicles that can be disbanded once specific goals are achieved rather than remain as ongoing entities.

Despite the conflicts that had to be negotiated, the partners stated that this project served as a mechanism to cement the value of collective actions. Without the creativity generated by the partnership, they believe the new model would not have been developed. Participants agreed that the partnership reduced the impact of the divisions created by competition, minimized duplication, and addressed service gaps. They indicated that, despite differences, they had managed to communicate and work through "sticky points" to reach their goal of developing a new model that they continued to believe would successfully promote health, even when funds were scarce. The two NGOs at the center of this partnership continue to have both a competitive and a collaborative relationship, competing for scarce funds, but cooperating to bring about broader change in the community when needed.

\section{Theme 4: Neutral Interpersonal Space Enabled the Partnership To Be Enacted}

Participants concluded that that the ability to create a neutral interpersonal space in which partners could interact was crucial. Unless members felt respected and valued, their participation would merely represent "tokenism," which was the case for community-based NGOs. They added that

\begin{tabular}{|c|c|}
\hline \multicolumn{2}{|r|}{ Table 4. Type of Conflict and Strategies } \\
\hline \multicolumn{2}{|r|}{ Participant Comments } \\
\hline \multicolumn{2}{|r|}{ Conflict } \\
\hline Selecting CALD communities & $\begin{array}{l}\text { We have so many CALD communities, we wanted to include them all for the project but there } \\
\text { is only so much funding ... there was a fair bit of tension there ... after much discussion it was } \\
\text { decided to go with four CALD communities. }\end{array}$ \\
\hline Communication issues via e-mail & $\begin{array}{l}\text { Even the best goodwill and good intent, things can go wrong just because you haven't got } \\
\text { the time to sit and talk through things, and keep everyone in the loop. We relied on e-mails } \\
\text { and that was open to misinterpretation and that was an issue. Mostly it was about clarity of } \\
\text { communication ... wherever there is a communication channel which is not necessarily trusted, } \\
\text { then the message can be misinterpreted. }\end{array}$ \\
\hline Funding issues & $\begin{array}{l}\text { There are limited sources of funding especially recurrent funding ...NGOs have to survive and } \\
\text { there is only one door to enter ... one place to beg, so we are forced to compete. }\end{array}$ \\
\hline \multicolumn{2}{|r|}{ Strategies } \\
\hline Seeking clarity & $\begin{array}{l}\text { If I had concerns, I don't let things sit and fester, I'd rather ask the person or people involved for } \\
\text { clarification, rather than put my own interpretation on what I think is happening } \ldots \text { this way we } \\
\text { can resolve issues straight away. }\end{array}$ \\
\hline Double checking e-mails & $\begin{array}{l}\text { I'd ask the person involved for clarification, rather than put my own interpretation on what I } \\
\text { think is happening. I double check e-mails to resolve issues straightaway. }\end{array}$ \\
\hline Embracing the partnership model & $\begin{array}{l}\text { I think the partnership approach is a model of best practice as best practice as projects such as } \\
\text { this can make a difference to the community. }\end{array}$ \\
\hline Openness and transparency & $\begin{array}{l}\text { Our openness and transparency ...we had laid it all on the table and said lets develop the model, } \\
\text { people always assume that governments come in with an agenda. }\end{array}$ \\
\hline
\end{tabular}


the university was ideally suited to create this neutral interpersonal space in which to allow the partnership to flourish. Participants described how cross-sectoral and interorganizational relationships had been diluted by the forced competitive nature of funding. The NGOs both believed that the best way to rebuild and maintain relationships of trust in this project was for the university to act as a buffer. Participants added that the university provided an opportunity for the organizations to engage in capacity building (e.g., learning how to use evidence, analyses data, and think critically). With this knowledge, members could handle competition using a "bottom-up" process instead of simply responding to imposed competition and its unintended consequences. Participants' comments in Table 5 elaborate on these views.

\section{DISCUSSION}

This paper has tracked the development of a partnership between a government department, two NGOs, and a university to develop a model of service delivery that could facilitate improved health and service usage by CALD communities. The partnership was driven by funding requirements, but the two NGOs agreed to partner to achieve the purpose of the project even though they had traditionally competed for funds. Both envisaged the benefits of developing a shared model of service delivery that could help their CALD communities. This altruistic approach was also found by Roussos and co-workers ${ }^{19}$ and Berry and colleagues, ${ }^{5}$ who stated that organizations often partner because they perceived collaboration to be a useful strategy to achieve outcomes in their com- munities. Funding to support a new model of service delivery was scarce, so the organizations sought partnership as a way of sharing the benefits of learning about a model that was based in evidence. Ubels and Greijin ${ }^{10}$ argued that funding could be better utilized through such partnerships rather than spreading funds across different organizations, leading to minimal impact. The partners in this study confirmed that sharing limited funds across their two organizations was equitable, but that partnering was a more efficient way to design and implement the model.

The university involvement was considered by the partners to be advantageous because it brought research expertise to drive the development of an evidence-based model that was perceived by the partners to be robust. ${ }^{9}$ For the researchers, engagement with the NGOs brought applied knowledge and experience that was invaluable. Zendell and associates ${ }^{21}$ suggested that universities can offer their intellectual and technological support to communities to help solve problems and, in so doing, become part of the community.

Respectful relationships were essential to hold the partnership together and assisted the partners to communicate with each other in times of tension. Given the historically imposed competitiveness between the NGOs, the partners were understandably cautious when interacting with each other during meetings and in e-mails. Thus, respectful relationships were necessary. However, excessive focus on respectful interactions between the partners sometimes compromised open discussion such that differences of opinion were glossed over rather than fully debated. Depersonalizing issues facilitated open

\begin{tabular}{|ll|}
\hline & Table 5. Need for Neutral Interpersonal Space in Partnerships \\
& Participant Comments \\
\hline Benefits & $\begin{array}{l}\text { Organizational partnerships are always enacted in that very interpersonal space and you need this space } \\
\text { to create real partnerships where people feel safe and can openly discuss differences and feel they are } \\
\text { contributing to something good... it is about relationships between people like over coffee I can discuss a } \\
\text { point of view even if I do not agree with the other's viewpoint, otherwise it becomes tokenism. }\end{array}$ \\
Role of the university & $\begin{array}{l}\text { The university was best to lead this project ... it had no vested interest. University brings in new skill sets } \\
\text { [research and evidence]. They bring intellectual capital that we could not possibly provide .....the university } \\
\text { plays a neutral role in bringing two providers who have been traditionally competitors to work together. }\end{array}$ \\
University brokering & $\begin{array}{l}\text { The university brokered and led the partnership by keeping us all focused on our objectives to aspire to the } \\
\text { same meaningful goal to develop the model. }\end{array}$ \\
University building capacity & $\begin{array}{l}\text { There is a way of dealing with competitiveness ....instead of trying to stop the top-down process of imposed } \\
\text { competition and unintended consequences we can encourage a bottom-up process, which is about how to } \\
\text { build capacity to manage competition between our organizations. }\end{array}$ \\
\hline
\end{tabular}


discussion and transparency. Participants believed that clear ground rules were necessary to manage conflict at the outset of the partnership, but that a balance between diplomacy and debate was needed.

Walker and co-workers ${ }^{16}$ describe partnership management as a developmental process where partners can learn to engage with each other in a trustful manner. Williams ${ }^{22}$ suggested that issues of time, trust, and turf usually became areas of contention when organizations work together. However, by having a common goal and a willingness to share power, responsibility, and accountability for achieving this goal, relationships within the partnership can be democratic and effective, as in the current study. Participants acknowledged their common goal to develop the new model. This common goal enabled them to move beyond previous tensions to produce a creative solution to a long-standing problem.

The partners used strategies to overcome tensions and challenges that arose within the partnership. The necessary use of e-mail resulted in unintended tension between the partners, because text phrases cannot convey the emotion underlying the electronic message. This disadvantage, coupled with lack of time to meet in person, contributed to the misunderstandings; however, participants mitigated this problem by actively seeking clarification at face-to-face-meetings and deliberately adding "mood" indicators to augment their text. There is ample literature to suggest that it may be prudent to follow up electronic communication with a telephone call to compensate for the lack of emotional tone in electronic communications. ${ }^{23}$ The pitfalls associated with this form of communication were evident.

The historical competition for funds between the two NGOs created conflict and was managed successfully. However, in the interests of financial efficiency, the NGOs elected to compete for funds when the new model was eventually implemented. This decision eventually undermined the partnership. Nevertheless, the NGOs successfully fulfilled the goal and purpose of the partnership. Although they struggled to engage fully with each other beyond the planning level, they were able to deeply engage with the university. This finding is congruent with that of Glazer and associates, ${ }^{9}$ who promoted universities as potentially impartial brokers within interorganizational collaborations. In this study, the university created a neutral interpersonal space within which to sustain the partnership for the duration of its purpose. Although the partnership was not sustained in the long term, differences were put aside for sufficient time to harness knowledge from all sectors to build a new model that was adopted successfully by the CALD communities.

This articles has described the benefit of bringing together traditionally competitive or diverse partners to generate new knowledge. For partnership managers, it is important to highlight this benefit of partnership working, especially when conflict emerges. Managers should seek neutral places in which to enact the partnership. They should overtly identify and encourage conflict mitigation strategies to address each risk to collaboration. Even when conflict emerges, managers need to be careful to balance diplomacy with debate to ensure all opinions are aired adequately. Finally, the longevity of the partnership should be discussed rather than assuming that it will continue.

\section{LIMITATIONS}

Because this research was qualitative and based on only a small sample, the findings are context specific and cannot be generalized. However, the findings do provide some insight into how complex partnerships function and how such partnerships may be purpose and time bound. It is important to understand and build this lessen into the design of the partnerships to achieve optimal outcomes. Extending partnerships beyond their reasonable purpose may be detrimental, leading to an inability to successfully mitigate conflict. It may be necessary to engage partners in open discussion about the longevity of the collaboration and plan reasonable exit points or opportunities when major objectives have been achieved. Although our findings can only be applied to similar contexts, they provide insights into how partnerships can be fraught with difficulties, but with strategic negotiations they can promote synergistic harmony towards the successful completion of clearly articulated goals.

\section{ACKNOWLEDGMENTS}

The authors acknowledge Gail Kerr (CEO AccesServices Inc.), Lesley Kelly (Community Navigator Project Manager), and Felket Kahsay (Community Navigator Mentor), as well as other staff of the NGOs and community members for valuable feedback and input into this manuscript. 
1. Guo C, Acar M. Understanding collaboration among nonprofit organisations: Combining resource dependence, institutional, and network perspectives. Non-profit and Voluntary Sector Quarterly. 2005;34(3):340-61.

2. Kohm A, LaPiana D. Strategic restructuring for non-profit organisations: Mergers, integrations and alliances. Westport (CT): Praeger; 2003.

3. Lewis JM. A network approach for researching partnerships in health. Australian \& New Zealand Health Policy. 2005;2:22.

4. Pietroburgo, J, Wernet p. Joining forces, fortunes, and futures: Restructuring and adaptation in non-profit hospice organisations. Non-profit Management \& Leadership. 2004;15(1):117-37.

5. Berry F, Brower S, Sang Ok Choi, Gao WX, Jang H, Kwon M, et al. Three traditions of network research: What the public management research agenda can learn from other research communities. Public Admin Rev. 2004;64(5):529-42.

6. McGuire M. Collaborative public management: Assessing what we know and how we know it. Public Admin Rev. 2006;66(1):33-43.

7. Oakerson RJ. Governing local public economics: Creating the civic metropolis. Oakland (CA): ICA Press; 1999.

8. Baker EA, Boulden N, Durham M, Lowell ME, Gonzalez M, et al. The Latino health advocacy program: A collaborative lay health advisor approach. Health Educ Behav. 1997;24(4):495-509.

9. Glazer G, Reid Ponte P, Stuart-Shor EM, Cooley ME. The power of partnership: Addressing cancer health disparities through an academic-service partnership. Nurs Outlook. 2008; 57(3):123-9.

10. Ubels J, Greijin H. Partnerships for service delivery: What makes them tick? Capacity.Org Journal. 2007;27.

11. Gazley B. Beyond the contract: The scope and nature of informal government-nonprofit partnerships. Public Admin Rev. 2007;68(1):141-54.
12. McDonald J. Contestability and social justice: The limits of competitive tendering of welfare services. Australian Social Work. 2002;55(2):99-108.

13. Sandfort JR. Trying to dance to syncopated rhythm: The dynamics of government funding for nonprofits. The Nonprofit Quarterly. 2004;13-7.

14. Austin JE. Strategic collaboration between nonprofit and business. Nonprofit and Voluntary Sector Quarterly. 2000;29(1):69-97.

15. Boris ET. Introduction-nonprofit organisation in a democracy: Varied roles and responsibilities. In Borsi ET, Steuerle CE, editors. Nonprofit and government: Collaboration and conflict. Washington: Urban Institute Press; 1998. pp. 3-29.

16. Walker R, Pietsch J, Delaney L, Hahn B, Wallace C, Billings K. Partnership management: Working across organisational boundaries. Aust J Primary Health. 2007;13(3):9-16.

17. Morgan DL. Focus groups as qualitative research, 2nd ed. Thousand Oaks (CA): Sage; 1997.

18. Krueger RA. Focus groups: A practical guide for applied research, 2nd ed. Thousand Oaks (CA): Sage; 1994.

19. Roussos ST, Fawcett SB. A review of collaborative partnerships as a strategy for improving community health. Annu Rev Public Health. 2000;21:369-402.

20. Streubert-Speziale HJ, Carpenter DR. Qualitative research in nursing: Advancing the humanistic imperative, 3rd ed. Philadelphia: Lippincott Williams \& Wilkins; 2003.

21. Zendell AL, Fortune AE, Mertz LKP, Oelewyn N. Universitycommunity partnerships in gerontological social work: Building consensus around student learning. J Gerontol Soc Work. 2007;50(1/2):155-72.

22. Williams p. The competent boundary spanner. Public Adm. 2002;80(1):103-24.

23. That's the problem with e-mail. The Clinical Advisor. 2009; 12(91):42. 
